\title{
Survey of Medical Student Empathy at a Canadian Medical School
}

Safina Adatia ( $\sim$ safina.adatia@mail.mcgill.ca )

McGill University

Pierre-Paul Tellier

McGill University

\section{Research Article}

Keywords: Empathy, patient-physician relationship, humanity, clinical curriculum, communication

Posted Date: December 8th, 2020

DOI: https://doi.org/10.21203/rs.3.rs-119795/v1

License: (c) (i) This work is licensed under a Creative Commons Attribution 4.0 International License. Read Full License 


\title{
Survey of Medical Student Empathy at a Canadian Medical School
}

A cross-sectional quantitative survey

\author{
First author: \\ Safina Adatia, MSc, MD Candidate* \\ McGill University \\ safina.adatia@mail.mcgill.ca \\ 514-207-0622 (mobile) \\ Twitter: @SAdatia \\ Safina Adatia is a final year medical student at McGill University.
}

\section{Second author:}

Dr. Pierre-Paul Tellier, MD, CFPC

Associate Professor, Department of Family Medicine

McGill University

pierre-paul.tellier@mcgill.ca

Pierre-Paul Tellier is an Associate Professor within the Department of Family Medicine at McGill University

Funding statement: None

We have no competing interests to declare.

EQUATOR network guidelines for research

Upon searching, no guidelines fit our cross-sectional survey design within the medical education category.

*corresponding author 


\begin{abstract}
Purpose:

Within a medical context, empathy is defined as "an appropriate understanding and communication of a patient's experience." While it has been established that empathy is an important quality to have as a future doctor, studies have shown that empathy in medical students declines during their clinical years. However, there are no studies to date that evaluate medical student empathy in Canada. Therefore, we aimed to evaluate medical student empathy at McGill University Medical School using the Jefferson Scale of Empathy (JSE).
\end{abstract}

\title{
Methods:
}

We used a cross-sectional study design and invited medical students across all 4 years, in October 2019 , to complete the JSE. The JSE is a validated psychometric tool that measures empathy at one point in time. The survey was distributed via email and on social media. We offered the chance for participants to win a prize if they completed the survey.

\section{Results:}

A total of 133 students from all 4 years responded, proportionate across each year. Differences in mean questionnaire were not statistically significant for gender $(\mathrm{p}=0.364)$, age $(\mathrm{p}=0.2746)$ or specialty interest $(\mathrm{p}=0.436)$. The ANOVA for differences in year of medical school was significant $(\mathrm{p}=0.0104)$. Between groups analysis revealed a statistically significant decrease between Med-2 empathy scores (average score 117.6) and Med-3 (107.5), $\mathrm{p}<0.01$.

\section{Conclusion:}

Our statistical analysis determined that medical students' empathy declines between the second and third year of medical school in a Canadian context, consistent with global results. This information can help us target changes in the medical curriculum to preserve empathy in students, and prevent this decline, which could then be applied to other medical schools internationally.

\section{Keywords:}

Empathy; patient-physician relationship; humanity; clinical curriculum; communication 
Survey of Medical Student Empathy at a Canadian Medical School

\section{Introduction}

Empathy is an important quality in a physician. It has been outlined as such by the CanMEDS framework developed by the Royal College of Physicians and Surgeons of Canada, and the College of Family Physicians of Canada, the professional organizations that drive medical school and residency curricula in Canada(1). Empathy is a complex construct. No one unified definition of empathy currently exists, as it may include emotional, cognitive and behavioural aspects(2). However, a commonly cited definition within medical literature is "an appropriate understanding and communication of the patient's experiences"(2). Therefore, our aim in this investigation is to assess empathy' levels among McGill medical students.

\section{Empathy in medical clinical practice}

In relation to the role of "Communicator", the CanMEDS framework states that physicians must establish a therapeutic role with their patients, and communicate using empathy and a patientcentred approach(1,3). Benefits to incorporating empathy into physician practice include improvements in patient satisfaction, trust and comfort(4-7) along with decreases in patient anxiety and stress, better clinical outcomes, and self-efficacy and shared decision-making(8, 9). Selfefficacy, the ability for patients to believe they are capable to cope with the challenges they face, improves adherence to treatment(10). Furthermore, doctors who are empathetic experience higher rates of job satisfaction and mental health(11), make better clinical decisions(12-15) and are more effective leaders in their field(16).

However, despite the fact that it constitutes an important aspect of empathy, current evidence points to a decreased interest in good physician-patient communication in medical general practice(8). What is more, it has been found that patients and physicians often perceive communication differently: doctors score their communication skills as consistent amongst their 
Survey of Medical Student Empathy at a Canadian Medical School

patients, whereas different patient scores demonstrate more variation for the same doctor $(8,17)$. In the same vein, doctors and patients rate physicians' communication skills differently(17). Some scholars claim that the increasing use of technology has changed the focus of care towards effectiveness and efficiency(18-20), resulting in a loss of empathy as an important practice.

\section{Empathy in undergraduate medical education}

It has been demonstrated that over the four years of medical training, attitudes of students towards patient suffering may change negatively $(21,22)$, with damaging consequences for future patients' clinical outcomes. Using the Jefferson Scale of Empathy (JSE) it was found that empathy significantly declined during the third year (known as clerkship) of medical school(23). These results show the importance of evaluating medical student empathy, in order to understand at what point empathy declines, so as to create potential solutions to this problem. McGill University's medical school has implemented a core component of the curriculum, known as Physicianship, that addresses concerns related to empathy, among other skills(24). While the goal of the development of this program was not to prevent drops in physician empathy, this program integrates formal courses throughout the four years of undergraduate medical education to engage students in self-reflection, empathy, and a broad understanding of the two roles physicians have: professionals and healers. While such a program has existed for many years, there has not been an assessment of students' empathy over the course of the four years of medical training, evaluating how it changes over time as the student proceeds through the curriculum.

This study aims to fulfil this knowledge gap. It will be guided by the following research question: To what extent are currently enrolled (2018-2019) McGill medical students, in the four years of the medical curriculum, "empathetic" according to the Jefferson Scale of Empathy. That is, in this investigation we aim to assess empathy levels among McGill medical students. 
Survey of Medical Student Empathy at a Canadian Medical School

\section{Methodology}

Research design and context. This study used a cross-sectional survey. The survey was administered to students in late October of the school year, in order to allow time for transition between years. This time period was prior to residency applications, and prior to the national licensing examination, which allowed fourth year students to participate. We allowed four weeks for the collection of data in order to provide sufficient time for students to complete the survey. Population of reference and sampling strategies. The population we targeted is composed by the totality of medical students at McGill University enrolled in the academic year 2018-2019: Med1, Med-2, Med-3 and Med-4's. We did not estimate any sample because our purpose is to involve as many students as possible of the four cohorts of students. Non-medical students, i.e. dental students who share classes in Year 1 and 2, were excluded.

\section{Data gathering}

Strategy

We recruited with the support of the Medical Students' Society (MSS), and submitted advertisements for the survey through the MSS Newsletter, The Murmur. We also advertised on social media through the class specific Facebook pages. We encouraged participation by offering prizes to participants. After completing the survey, students were invited to register for a draw, using a link to a separate site, to be randomly selected for one of 6 Visa credit cards valued at $\$ 50$ each.

We used the technological platform known as Survey Monkey (https://www.surveymonkey.com/mp/global/canada/) to collect our data. 
Survey of Medical Student Empathy at a Canadian Medical School

\section{Tool for Gathering Data - The Jefferson Scale of Empathy}

The instrument that we used to measure empathy in McGill medical students is the Jefferson Scale of Empathy (JSE). The JSE is a reliable, validated, international tool used to assess empathy in medical students, and health professions students(25). It was developed because of a lack of a validated, psychometric scale to measure medical student, resident, and physician empathy, specifically in patient care situations(26). While the scale has been used to assess student empathy in the United States along with other countries, to our knowledge it has so far never been used in the Canadian medical student context.

The questionnaire includes 20 items, 10 positively worded and 10 negatively worded, answered on a Likert scale from 1 (strongly disagree) to 7 (strongly agree). Participants are scored from 20-140, with higher scores indicating greater empathy.

\section{Data Analysis}

We computed descriptive statistics and their intervals per cohort. Multivariate analysis was performed to compare cohorts. RStudio software was used to conduct the analysis.

\section{Statement on ethical consideritations}

We obtained ethics approval from the McGill Faculty of Medicine Research and Ethics Compliance Board.

\section{Results}

\section{Descriptive statistics}

A total of 133 students responded: 41 from Med-1 (23\% of the cohort), 30 from Med-2 (17\% of the cohort), 29 from Med-3 (16\% of the cohort), and 33 from Med-4 (18\% of the cohort). 
92 respondents were female, and 38 were male, with 2 preferring not to answer and 1 transgender male. Table 1 demonstrates responses by year of medical school.

Table 1: Number of responses per year

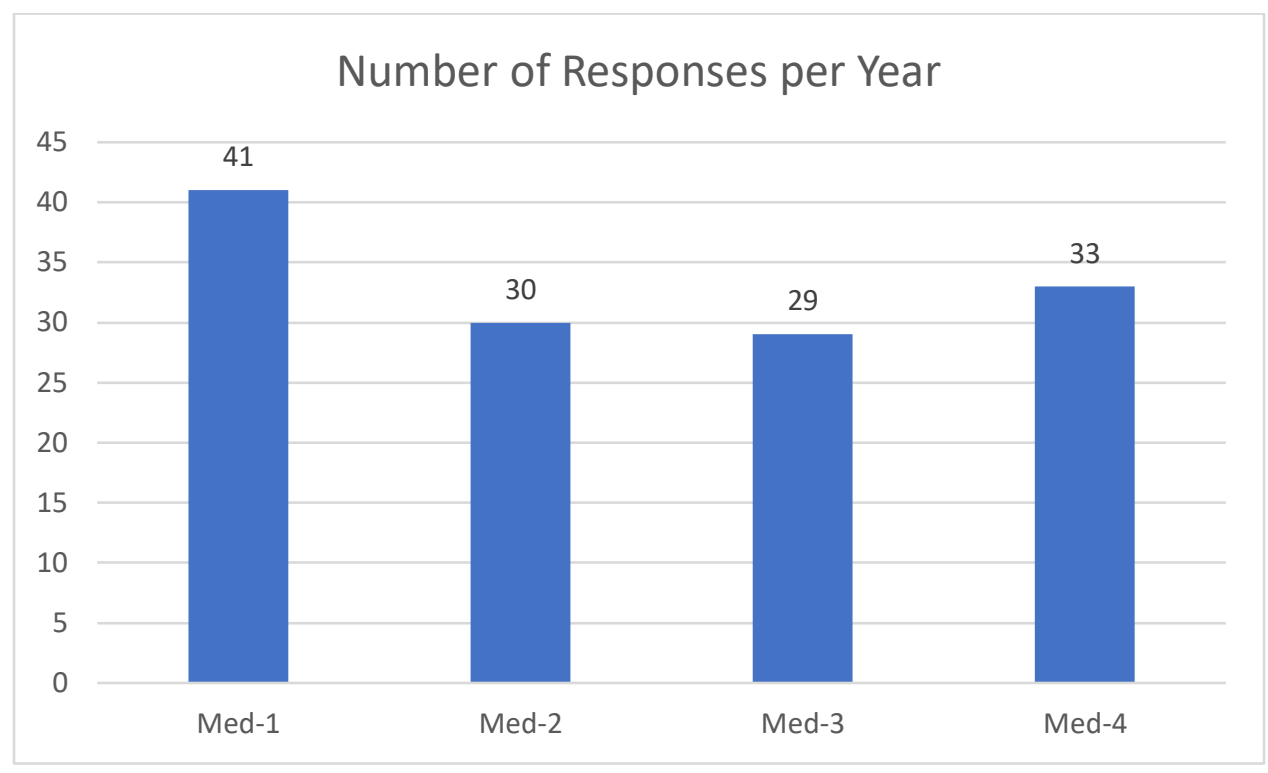

\section{Statistical Analysis}

An ANOVA (analysis of variance) was used to compare mean empathy scores between groups for gender (male vs. female vs. other), age (under 22 to represent medical students accepted directly from pre-university colleges vs. over 22 for all other students), specialty interest (medical specialties vs. surgical specialties vs. undecided) and year in medical school (Med 1 vs Med 2 vs Med 3 vs Med 4). Tables 2-5 show the differences in mean scores for the various categories. The 2 who preferred not to answer regarding their gender, and 1 transgender male were combined in the analysis as "other" to protect anonymity.

Differences in mean questionnaire were statistically insignificant for gender $(\mathrm{p}=0.364)$, age $(\mathrm{p}=0.2746)$ and specialty interest $(\mathrm{p}=0.436)$. Interestingly, the ANOVA for differences in year of medical school was significant $(\mathrm{p}=0.0104)$. Between groups analysis revealed a statistically significant difference between only Med-3 empathy scores (average score 107.5) and Med-2 (117.6), $\mathrm{p}<0.01$. 
Survey of Medical Student Empathy at a Canadian Medical School

Table 2: Mean questionnaire score by gender

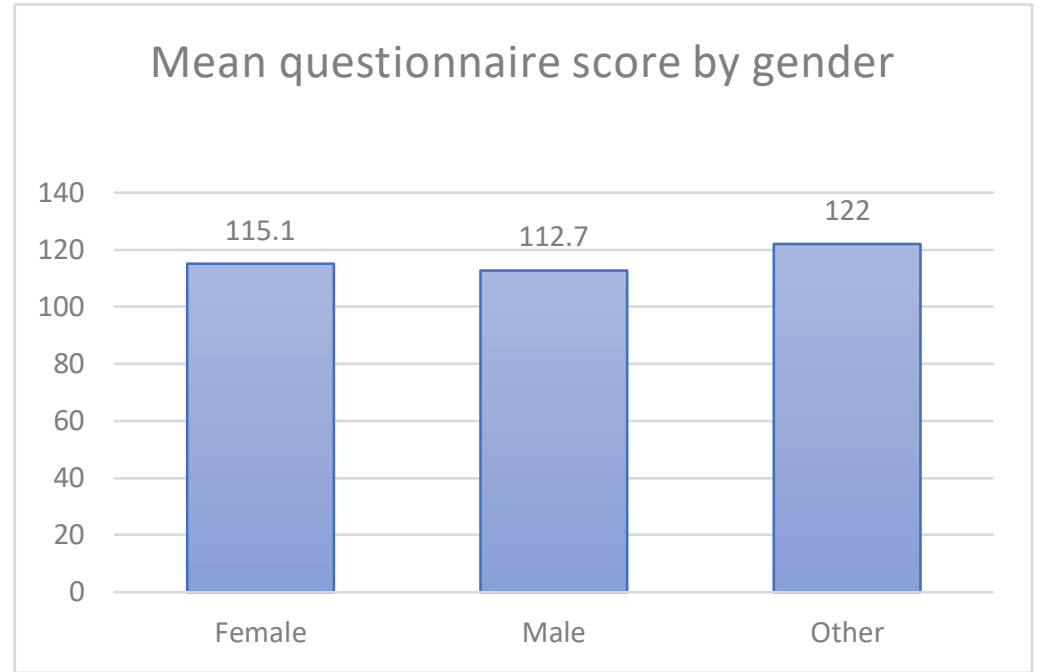

Table 3: Mean questionnaire score by age

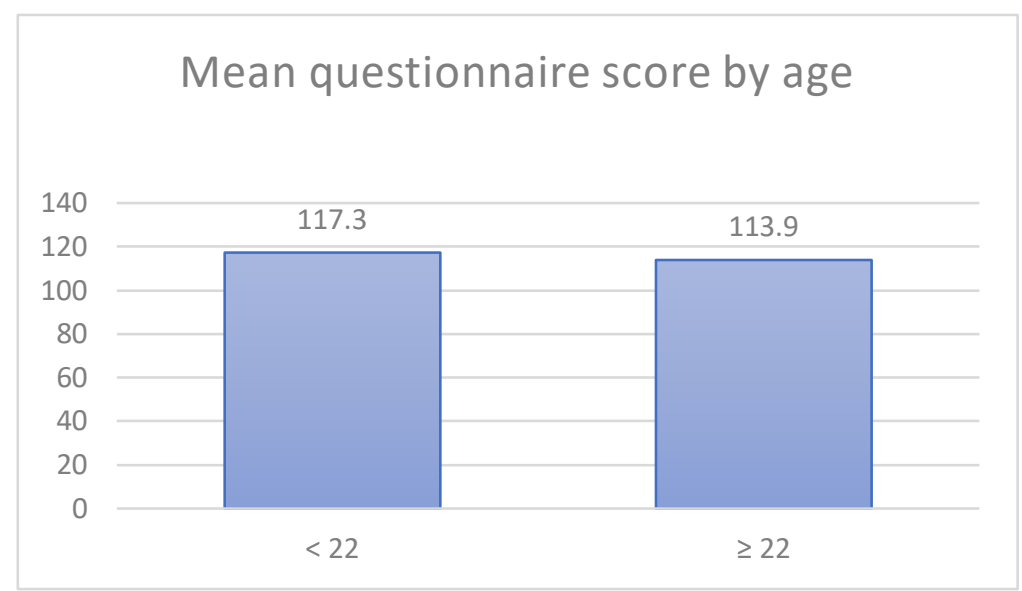


Survey of Medical Student Empathy at a Canadian Medical School

Table 4: Mean questionnaire score by specialty interest

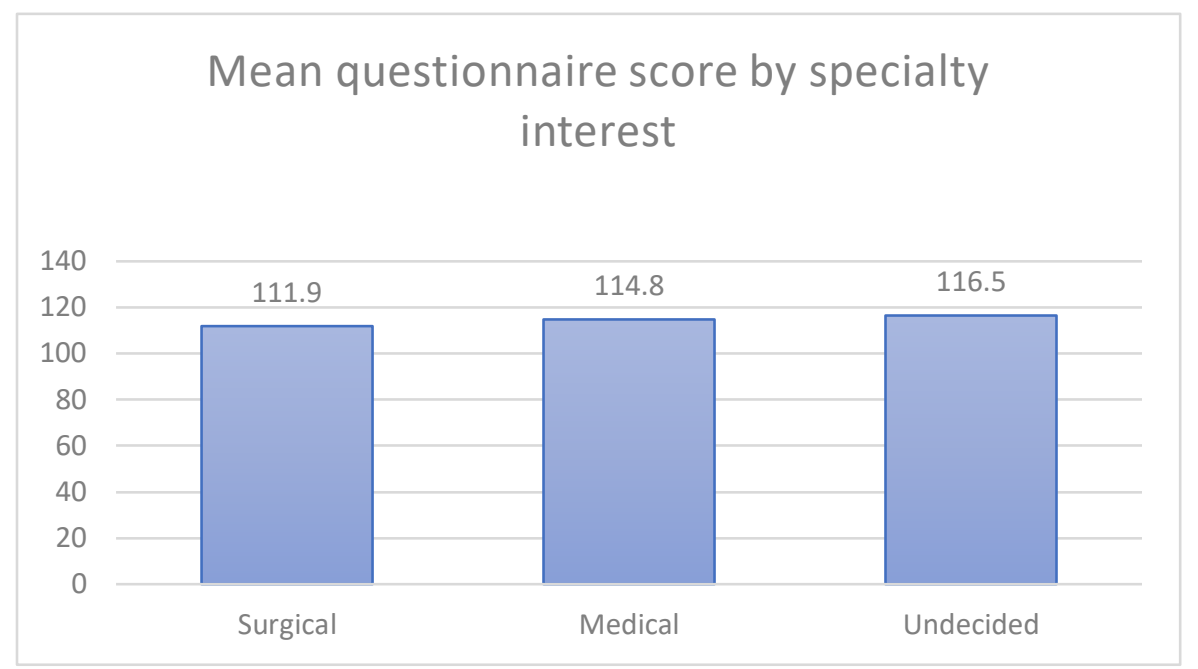

Table 5: Mean questionnaire score by year in medical school

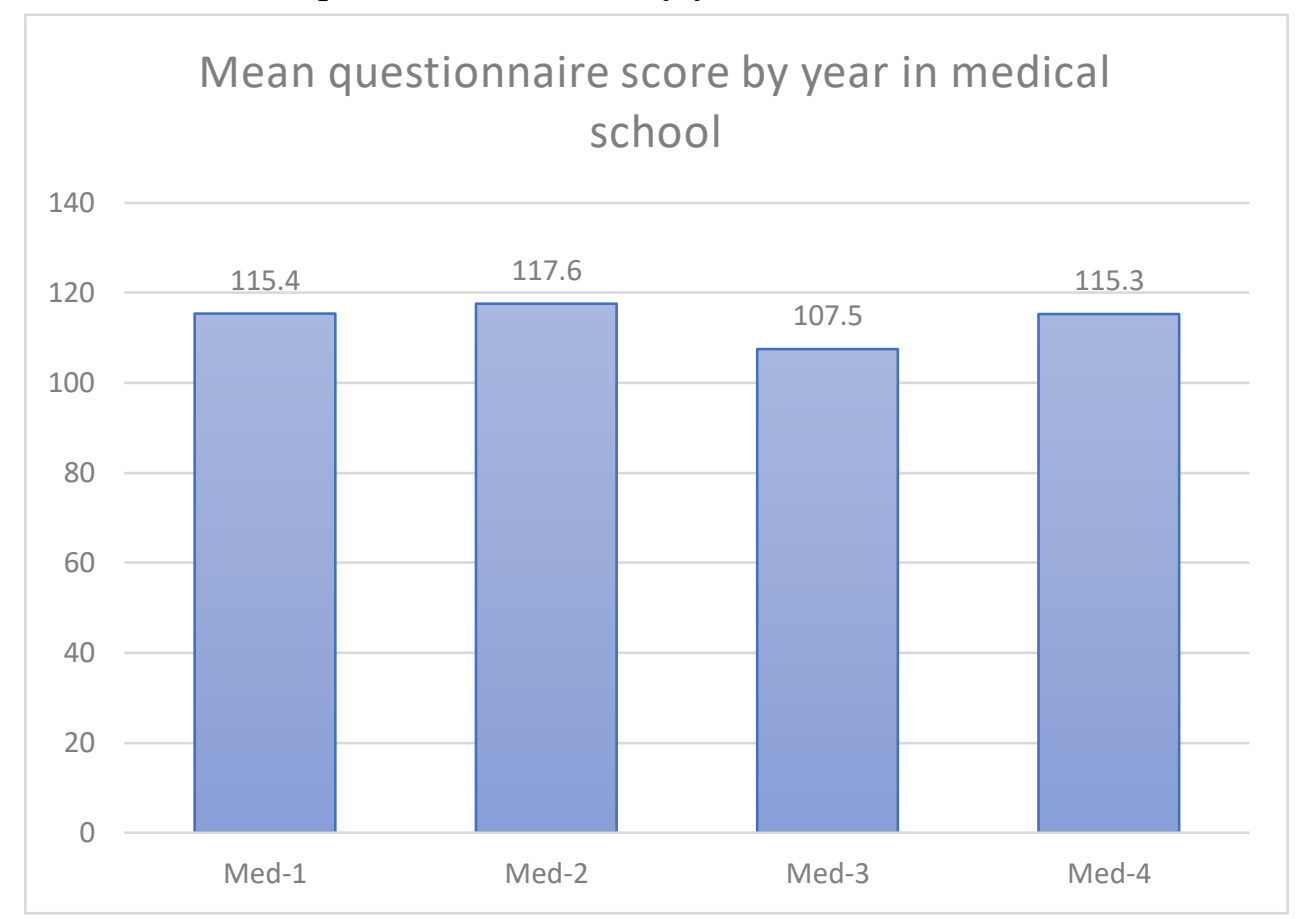

\section{Discussion}

This study evaluated medical student empathy scores at McGill University. The goal of the study was to assess differences in empathy based on gender, age, specialty of interest and year in medical school. While gender, age, and desired specialty did not result in significant differences, 
Survey of Medical Student Empathy at a Canadian Medical School

year in medical school did - specifically, we found a difference in empathy score between Med-2 and Med-3. While this and other studies with medical students do not assess specific behaviour, one report demonstrated a positive correlation between empathy scores in medical school and ratings of empathetic behaviour in residency, suggesting that the JSE can help predict empathy longitudinally(27).

The results mirror findings found in other medical student empathy studies, where students seem to experience a drop in empathy as they begin their clinical, in hospital training $(28,29)$. There are various potential reasons as to why this may happen. A systematic review conducted in 2011 by Neumann et al, in Germany(30) investigated and summarized reasons for changes in medical student empathy. Some studies found that students who were more interested in "patientoriented" specialties had higher rates of empathy compared to those who were interested in "patient-remote" specialties (surgery, radiology)(30), though we did not find a difference in empathy score based on specialty. The authors also found that "distress" which included burnout, lack of sleep, depression, low self-worth and reduced quality of life influenced self-assessed empathy in students and in fact, is the main reason for such an empathy decline(30). The common denominators described in their literature review include mistreatment from mentors and preceptors, where medical students may experience harassment and belitting at the hands of their superiors, increased vulnerability as they are exposed to the reality of death and dying, reduced social support and increased isolation, and a high workload. Other potential causes of a decline in empathy may be related to short patient lengths of stay resulting in distorted learning experiences, difficult learning environments (little time for bedside teaching and unstructured studying), along with inadequate role models, combined with idealized characters of what physicians should be in the media(30). These could potentially explain our finding of a decrease in empathy between basic 
Survey of Medical Student Empathy at a Canadian Medical School

science years and clerkship. Further qualitative analysis examining why students experience a decline in empathy within a Canadian context would be useful to better understand our findings.

Interestingly, our study differed from other medical student empathy studies in that mean empathy scores increased after third year (mean empathy score in Med-3 being 107.5 and in Med 4 being 115.3). However this difference was not statistically significant. These findings may be attributed to the fact that the majority of Med-4 includes elective rotations that students' themselves select, and therefore are usually based on interest, potentially resulting in increased enjoyment of the rotations. Additionally, elective rotations tend to have less call and students are able to work less hours than core rotations. Qualitative analysis of experiences in third vs. fourth year would be important to explain this data.

Limitations to our study include the fact that the empathy scores are self-reported. It does not assess objective behaviour towards patients, but students' own feelings of empathy. That being said, multiple other studies have performed the same research and found a similar decline between the second and third year of medical school, therefore our results are consistent with the vast majority of similar studies. Additionally, our results represent approximately $20 \%$ of all medical students, though we did have similar response rates amonst the various years. Repeating the study with greater participation may provide us with further insight into differences amongst students by specialty (patient-oriented vs patient-remote), gender, and age group - categories where we did not find differences, but that have been found elsewhere. Finally, this is a quantitative study and we are unable to draw conclusions as to why empathy declines. Further qualitative research into the changes that occur between second and third year will provide insight as to why empathy declines, so curricula can adapt accordingly. 
Survey of Medical Student Empathy at a Canadian Medical School

\section{Conclusion}

Empathy is an important quality necessary for a fruitful physician-patient relationship. Previous studies have assessed empathy in medical students across the four years of their training, however none to our knowledge assessed empathy within a Canadian medical school context. This study helped us understand the change in empathy during medical school according to year, age, gender, and desired specialty after graduation at a Canadian medical school. Our study found a significant decline in empathy between the second and third years of medical school, consistent with results globally. It is unclear what factors into this decline, however further research with greater participation from the medical student body, and qualitative data will help us discover such information, to potentially adapt the medical curriculum. 
Survey of Medical Student Empathy at a Canadian Medical School

\section{Abbreviations}

JSE - Jefferson Scale of Empathy

ANOVA - Analysis of Variance

MSS - Medical Students' Society 
Survey of Medical Student Empathy at a Canadian Medical School

\section{Declarations}

Ethics approval and consent to participate

Ethics approval was obtained from the McGill Research Ethics and Compliance Board. Informed consent was obtained from each participant.

Consent for publication

Not applicable.

Availability of data and materials

All data from this study is available in this report along with the supplementary tables.

Competing Interests

We have no financial or non-financial competing interests to declare.

Funding

The author Safina Adatia (SA) received a research bursary of $\$ 2000$ to compensate for time spent on the project. The author Dr. Pierre-Paul Tellier (PPT) used residual funds ( $\$ 1000$ approx) from various public grants to fund this project.

Authors' contributions

SA wrote the main manuscript text and prepared figures. PPT supervised, reviewed and edited the manuscript and all figures. All authors reviewed the final draft of the manuscript.

Acknowledgements

Not applicable.

\section{Author Information}

SA is a final year medical student at McGill University. She also has a Master's in Family Medicine from McGill University and hopes to become a family physician in the future. She is passionate about empathy within medical training.

PPT is an Associate Professor within the Department of Family Medicine and is active in teaching medical learners. He also has a special interest in empathy during medical training.

All methods were carried out in accordance with relevant guidelines and regulations. 
Survey of Medical Student Empathy at a Canadian Medical School

\section{References}

1. Canada RCoPaSo. CanMEDS: Better standards, better physicians, better care: Royal College of Physicians and Surgeons of Canada; 2018 [Available from:

http://www.royalcollege.ca/rcsite/canmeds/canmeds-framework-e.

2. Eikeland H-L, Ørnes K, Finset A, Pedersen R. The physician's role and empathy - a qualitative study of third year medical students. BMC Medical Education.

2014;14(1):165.

3. Shaw E OI, Fowler N, eds. CanMEDS-FM 2017: A competency framework for family physicians across the continuum. Mississauga, ON: The College of Family Physicians of Canada; 2017.

4. Thom DH. Physician behaviors that predict patient trust. The Journal of family practice. 2001;50(4):323-8.

5. Krupat E, Bell RA, Kravitz RL, Thom D, Azari R. When physicians and patients think alike: patient-centered beliefs and their impact on satisfaction and trust. The Journal of family practice. 2001;50(12):1057-62.

6. Reis HT, Clark MS, Pereira Gray DJ, Tsai F-F, Brown JB, Stewart M, et al. Measuring Responsiveness in the Therapeutic Relationship: A Patient Perspective. Basic and Applied Social Psychology. 2008;30(4):339-48.

7. Kim SS, Kaplowitz S, Johnston MV. The effects of physician empathy on patient satisfaction and compliance. Evaluation \& the health professions. 2004;27(3):237-51.

8. Derksen F, Bensing J, Lagro-Janssen A. Effectiveness of empathy in general practice: a systematic review. The British journal of general practice : the journal of the Royal College of General Practitioners. 2013;63(606):e76-84.

9. Zachariae R, Pedersen CG, Jensen AB, Ehrnrooth E, Rossen PB, von der Maase H. Association of perceived physician communication style with patient satisfaction, distress, cancer-related self-efficacy, and perceived control over the disease. British journal of cancer. 2003;88(5):658-65.

10. Vermeire E, Hearnshaw H, Van Royen P, Denekens J. Patient adherence to treatment: three decades of research. A comprehensive review. Journal of clinical pharmacy and therapeutics. 2001;26(5):331-42.

11. Gleichgerrcht E, Decety J. The relationship between different facets of empathy, pain perception and compassion fatigue among physicians. Frontiers in behavioral neuroscience. 2014;8:243.

12. Larson EB, Yao X. Clinical empathy as emotional labor in the patient-physician relationship. Jama. 2005;293(9):1100-6.

13. Levinson W, Gorawara-Bhat R, Lamb J. A study of patient clues and physician responses in primary care and surgical settings. Jama. 2000;284(8):1021-7.

14. Coulehan JL, Platt FW, Egener B, Frankel R, Lin CT, Lown B, et al. "Let me see if i have this right...": words that help build empathy. Annals of internal medicine. 2001;135(3):221-7.

15. Beckman HB, Frankel RM. Training practitioners to communicate effectively in cancer care: it is the relationship that counts. Patient education and counseling. 2003;50(1):85-9.

16. Skinner C, Spurgeon P. Valuing empathy and emotional intelligence in health leadership: a study of empathy, leadership behaviour and outcome effectiveness. Health services management research. 2005;18(1):1-12. 
Survey of Medical Student Empathy at a Canadian Medical School

17. Kenny DA, Veldhuijzen W, Weijden T, Leblanc A, Lockyer J, Legare F, et al. Interpersonal perception in the context of doctor-patient relationships: a dyadic analysis of doctor-patient communication. Social science \& medicine (1982). 2010;70(5):763-8.

18. Shapiro J. Walking a mile in their patients' shoes: empathy and othering in medical students' education. Philosophy, ethics, and humanities in medicine : PEHM. 2008;3:10.

19. Spiro H. Commentary: The practice of empathy. Academic medicine : journal of the Association of American Medical Colleges. 2009;84(9):1177-9.

20. Back AL, Arnold RM, Baile WF, Edwards KA, Tulsky JA. When praise is worth considering in a difficult conversation. Lancet (London, England). 2010;376(9744):8667.

21. Woloschuk W, Harasym PH, Temple W. Attitude change during medical school: a cohort study. Medical education. 2004;38(5):522-34.

22. Neumann M, Edelhauser F, Tauschel D, Fischer MR, Wirtz M, Woopen C, et al. Empathy decline and its reasons: a systematic review of studies with medical students and residents. Academic medicine : journal of the Association of American Medical Colleges. 2011;86(8):996-1009.

23. Hojat M, Mangione S, Nasca TJ, Rattner S, Erdmann JB, Gonnella JS, et al. An empirical study of decline in empathy in medical school. Medical education. 2004;38(9):934-41.

24. University M. Physicianship 2018 [Available from: https://www.mcgill.ca/ugme/curriculum/curriculum-components/physicianship.

25. Kane GC, Gotto JL, Mangione S, West S, Hojat M. Jefferson Scale of Patient's Perceptions of Physician Empathy: Preliminary Psychometric Data. Croatian medical journal. 2007;48(1):81-6.

26. Hojat M, Gonnella JS, Mangione S, Nasca TJ, Magee M. Physician empathy in medical education and practice: experience with the Jefferson scale of physician empathy. Seminars in Integrative Medicine. 2003;1(1):25-41.

27. Hojat M, Mangione S, Nasca TJ, Gonnella JS, Magee M. Empathy scores in medical school and ratings of empathic behavior in residency training 3 years later. The Journal of social psychology. 2005;145(6):663-72.

28. Chen D, Lew R, Hershman W, Orlander J. A Cross-sectional Measurement of Medical Student Empathy. Journal of General Internal Medicine. 2007;22(10):1434-8.

29. Chen DCR, Kirshenbaum DS, Yan J, Kirshenbaum E, Aseltine RH. Characterizing changes in student empathy throughout medical school. Medical Teacher. 2012;34(4):305-11.

30. Neumann M, Edelhäuser F, Tauschel D, Fischer MR, Wirtz M, Woopen C, et al. Empathy Decline and Its Reasons: A Systematic Review of Studies With Medical Students and Residents. Academic Medicine. 2011;86(8):996-1009. 


\section{Supplementary Files}

This is a list of supplementary files associated with this preprint. Click to download.

- BMCMedicalEducationTablesSafinaAdatiav3.docx 